\title{
PRACTICES OF HYDRO-METEOROLOGICAL SUPPORT DURING CONSTRUCTION PERIOD OF LARGEHYDROPOWER PROJECT
}

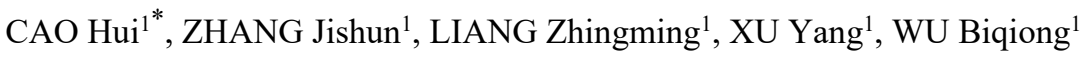 \\ ${ }^{1}$ Three Gorges Cascade Dispatching Communication Center, CHINA THREE GORGES CORPORATION, China
}

\begin{abstract}
The hydrological and meteorological hydro-meteorological support is one important part of the hydropower construction. Accidents caused by flood and rainstorm during construction will be reduced effectively with the help of reliable hydrological and meteorological forecast which also provides critical technical support for flood prevention and construction organization of projects under construction. Based on the practice of the hydro-meteorological support during the construction period of Three Gorges and Jinsha River cascade hydropower station, this article discussed the methods to support and serve hydro meteorology of large-scale cascade hydropower station construction. Meanwhile, this paper also builds up a hydro-meteorology supportive system for hydro-power station under construction which is led by a hydropower development company and associated by local professional institutions. And this research can also be utilized as a reference for other large-scale hydro-power station construction and to support the hydro-meteorology safeguard during the operation period.
\end{abstract}

\section{INTRODUCTION}

As the infrastructure, hydropower project is becoming more and more important in the national economy, and it is also very important to the economic benefit. The construction site of large-scale water conservancy projects with the poor natural environment, especially in the construction period, the construction facilities are mostly temporary buildings, and the ability to resist natural disasters is poor ${ }^{[1]}$. Therefore, hydrological and meteorological support services during construction are very important in engineering measure directly affecting the construction of the project. To carry out the support service of hydro meteorological during the construction period, to provide timely and reliable hydrological and meteorological forecast and warning information for engineering construction, accidents triggered by heavy rain and floods can be effectively reduced ${ }^{[2]}$. It is to provide important technical support for the safety of the flood season in the construction period, and it is the accumulating basic data for the analysis of climate change in the operation period of the power station ${ }^{[3]}$.

\section{WORK CONTENT AND MECHANISM}

The main task of hydro-meteorological support during construction period of large hydropower project is to provide technical support for the determination of characteristic parameters and rechecking of design parameters, construction organization and arrangement in the construction period.it is also to provide real-time hydrological and meteorological forecast and early warning and protection services for the safety of the flood season.

(1) To establish communication, contact and consultation mechanism with the hydrometeorological specialized institutions such as the state, local and basin, and to realize the sharing of resources;

(2) To establish coordination mechanisms with flood control departments and reservoir management unit of the upstream dam, when there are special circumstances, through the flood control departments to coordinate the implementation of upstream basin flood peak, ensure the safety of engineering;

(3) To establish joint defense mechanism with provincial, municipal and county meteorological organizations, grasp the process of regional disastrous weather change and forecast, implement linkage response, and improve the accuracy and effective foresight of disaster weather prediction and early warning in the dam area.

\section{SYSTEM CONSTRUCTION}

The system construction of hydrological and meteorological support should include an automatic system of hydrologic data collection and transmission, hydrological forecasting system, meteorological monitoring, and information processing system, weather forecasting system and so on. According to the sediment characteristics of the river and the characteristics of the reservoir, on the basis of the construction of the understructure hydrological and meteorological support system, the sediment monitoring and analysis system can

*Cao hui: cao_hui@ctg.com.cn 
be established. The system should be designed and constructed in accordance with the principles of unified planning, implementation by stages and gradual improvement.

\subsection{THE AUTOMATIC SYSTEM OF HYDROLOGIC DATA COLLECTION AND TRANSMISSION}

The automatic system of hydrologic data collection and transmission is composed of a telemetry station network and central station. By using advanced technology such as a sensor, communication, network, and computer, we can collect, transmit and process the elements such as water level, flow rate and rainfall in the watershed and engineering dam area automatically.

\subsection{Hydrological Forecasting System}

The hydrological forecasting system includes the shortterm water situation forecast system and the medium long term water forecast system. The specific function is shown in Table 1.

Table 1. The function of the hydrological forecasting system

\begin{tabular}{|c|c|}
\hline Item & Functional requirements \\
\hline $\begin{array}{l}\text { The short- } \\
\text { term } \\
\text { hydrological } \\
\text { forecasting } \\
\text { system }\end{array}$ & $\begin{array}{l}\text { 1.The realization of a database query, retrieval, } \\
\text { processing, display and analysis the basin real- } \\
\text { time rainfall through the system of GIS; } \\
\text { 2. The system can be automatically forecast } \\
\text { and real-time correction and the calculation } \\
\text { period is set at any time; } \\
\text { 3. A variety of forecasting methods and } \\
\text { forecasting models are realized at the same } \\
\text { time, and the interactive analysis and real-time } \\
\text { correction of the calculation process and results } \\
\text { can be carried out; } \\
\text { 4.Forecasting results in storage, graphic } \\
\text { display, and a data output; } \\
\text { 5.Historical flood process return test; } \\
\text { 6.Parameter rate determination of flood process } \\
\text { model; } \\
\text { 7.Prediction accuracy evaluation. }\end{array}$ \\
\hline $\begin{array}{l}\text { Medium } \\
\text { and long } \\
\text { term } \\
\text { hydrological } \\
\text { forecasting } \\
\text { System }\end{array}$ & $\begin{array}{l}\text { 1. Combining traditional forecasting of } \\
\text { mathematical statistics and synoptic science } \\
\text { with modern artificial intelligence prediction } \\
\text { technology; } \\
\text { 2. Forecast of annual, seasonal, monthly and ten } \\
\text { days flow characteristic value; } \\
\text { 3.Automatic optimization and synthesis of } \\
\text { many kinds of forecast results; } \\
\text { 4.Prediction accuracy evaluation. }\end{array}$ \\
\hline
\end{tabular}

\subsection{Meteorological monitoring and information processing system}

The meteorological monitoring and information processing system is used to monitor the real-time changes of the meteorological elements in the atmosphere and the ground of the dam area, and provide basic information support for the weather forecast and early warning for the flood. The system is composed of ground meteorological observation in the dam area, aerological sounding, weather radar detection, satellite cloud picture, and lightning monitoring. The specific function is shown in Table 2.

Table2.The function of meteorological monitoring and information processing system

\begin{tabular}{|c|c|}
\hline Item & Functional requirements \\
\hline $\begin{array}{l}\text { Ground } \\
\text { meteorological } \\
\text { observation in } \\
\text { the dam area }\end{array}$ & $\begin{array}{l}\text { 1. The observational items include } \\
\text { rainfall, air temperature, air pressure, } \\
\text { humidity, wind speed, wind direction, } \\
\text { ground temperature, evaporation, } \\
\text { sunshine, and radiation; } \\
\text { 2.Setting up a meteorological observation } \\
\text { station in the dam area according to the } \\
\text { principle of combining artificial } \\
\text { observation with automatic observation; } \\
\text { 3. According to the terrain and climate } \\
\text { characteristics of the dam area, the } \\
\text { automatic weather station should be } \\
\text { arranged on the upper and lower reaches } \\
\text { of the dam site, the left, and right banks } \\
\text { and the different elevation. }\end{array}$ \\
\hline $\begin{array}{l}\text { Aerological } \\
\text { sounding }\end{array}$ & $\begin{array}{l}\text { 1. Receiving and processing different } \\
\text { height field detection data and other } \\
\text { meteorological information; }\end{array}$ \\
\hline $\begin{array}{c}\text { Weather radar } \\
\text { detection }\end{array}$ & $\begin{array}{l}\text { To receive and deal with the real-time } \\
\text { monitoring data of Doppler weather radar } \\
\text { in the surrounding provinces and cities of } \\
\text { the dam area. }\end{array}$ \\
\hline $\begin{array}{l}\text { Satellite cloud } \\
\text { picture }\end{array}$ & $\begin{array}{l}\text { Reception and processing of } \\
\text { meteorological satellite data from the } \\
\text { National Satellite Center. }\end{array}$ \\
\hline $\begin{array}{l}\text { Lightning } \\
\text { monitoring }\end{array}$ & $\begin{array}{l}\text { Monitoring the atmospheric electric field } \\
\text { around the dam area and tracking the } \\
\text { development of lightning. }\end{array}$ \\
\hline
\end{tabular}

\subsection{Weather forecasting system}

According to the needs of the project and the situation of the site, a long, medium and short term prediction model is established, and the meteorological forecast results in different prediction periods are made, mainly including the following aspects:

(1) Based on the Doppler weather radar, combined with the automatic meteorological station, satellite cloud 
picture, numerical prediction, sounding data, electric field intensity data, establishing dam heavy rain, thunderstorms and windy weather tracking forecast model, making $0 \sim 6$ hours short of the disastrous weather forecast.

(2) Based on the numerical prediction products and meteorological observation data, combined with the technical methods of dynamic interpretation, grey prediction, optimization forecast, and batching method, the medium and short term prediction model in dam area is established.

(3) The long-term climate trend prediction of the dam area is carried out by various kinds of analysis and prediction methods by using various methods of climate diagnosis and prediction.

\subsection{SEDIMENT MONITORING AND ANALYSIS SYSTEM}

The construction of hydropower facilities in the sediment-laden river is necessary to carry out the sediment test and analysis work to provide technical support for the accurate prediction of the water level change in important sections of the dam area during construction. The system has consisted of two parts: database and application. The database has consisted of sediment base database and spatial database. The system has the functions of basic data management, hydrologic and sediment analysis, river bed evolution analysis, three-dimensional visual application, and prediction of sediment change trend.

\section{HYDROMETEOROLOGICALSUPPORT}

Hydrological and meteorological support services for large-scale water conservancy projects should need to carry out such works as hydrological and meteorological forecasting and warning, sediment monitoring, station maintenance, technical analysis, information release, emergency management, and data compilation.

\subsection{Forecasting and warning}

The main contents of the forecasting and warning service for the construction period of large water conservancy projects are shown in Table 3.

Table3.The content of hydrometeorological forecast and early warning

\begin{tabular}{|c|l|}
\hline \multicolumn{1}{|c|}{ Item } & \multicolumn{1}{c|}{ Content } \\
\hline \multirow{2}{*}{$\begin{array}{c}\text { Hydrological } \\
\text { forecasting } \\
\text { and warning }\end{array}$} & $\begin{array}{l}\text { 1.Forecast of the precipitation trend, the } \\
\text { total amount of water and the maximum } \\
\text { flow rate of the dam control catchment } \\
\text { before the flood season; } \\
\text { the total flow and extreme value in the } \\
\text { next month of the dam; } \\
\text { 3. At the end of ten days, the forecast of }\end{array}$ \\
\hline
\end{tabular}

\begin{tabular}{|c|c|}
\hline & $\begin{array}{l}\text { extreme value flow in next } 10 \mathrm{~d} \text {; } \\
\text { 4.Daily forecast of extreme value flow of } \\
\text { the } 3 \sim 7 \mathrm{~d} \text { in the future; } \\
\text { 5.Daily forecast the flow and water level } \\
\text { of the next } 48 \text { hours; } \\
6 \text {. Tracking rolling forecast during the } \\
\text { period of flood and super standard water. }\end{array}$ \\
\hline $\begin{array}{c}\text { Weather } \\
\text { forecasting } \\
\text { and warning }\end{array}$ & $\begin{array}{l}\text { 1.Prediction of weather factors such as } \\
\text { temperature and rainfall in flood season } \\
\text { of dam area before flood season; } \\
\text { 2. At the end of the quarter, forecast of } \\
\text { meteorological factors such as } \\
\text { temperature and rainfall in the next } \\
\text { quarter of the dam; } \\
\text { 3. At the end of the month, prediction of } \\
\text { rainfall process and climate trend in the } \\
\text { dam area of the next month; } \\
\text { 4. At the end of ten days, prediction of } \\
\text { temperature and precipitation in the next } \\
\text { ten days of the dam area; } \\
\text { 5.Daily production of extreme } \\
\text { temperature and precipitation process in } \\
\text { the future } 3 \mathrm{~d} \sim 7 \mathrm{~d} \text {; } \\
\text { 6.The daily production for the next } 48 \\
\text { hours in the rain, precipitation, wind } \\
\text { speed, air temperature, and relative } \\
\text { humidity; } \\
\text { 7. Forecast in the key period of } \\
\text { construction. }\end{array}$ \\
\hline
\end{tabular}

\subsection{Sediment monitoring}

The sediment monitoring and research plan of the dam area and the reservoir area of the hydropower station should be compiled, In accordance with the annual sediment monitoring implementation plan, the sediment monitoring work in the dam and reservoir areas of the year is carried out, includes the local underwater topographic survey and the measurement of the change of the main cross section of the dam area.

\subsection{Station maintenance}

Establish the inspection and maintenance management system of equipment and facilities in the station and office area, and stipulate the inspection content, the frequency of inspection, the form of inspection, the emergency repair and so on. Periodic inspection and maintenance of hydrological stations and equipment, ground meteorological stations and equipment, high altitude detection equipment and equipment in the office of engineering site. Set up the equipment running log, record the operation status of each equipment, inspection maintenance, equipment defect, diagnostic test and so on. 


\subsection{Technical analysis}

In the process of Hydrometeorological service, the research work should be carried out including the review of the engineering parameters, the hydrometeorology special analysis and so on. The content of the specific analysis is shown in Table 4.

Table 4.the content of analysis and research for hydrometeorological support

\begin{tabular}{|c|l|}
\hline \multicolumn{1}{|c|}{ Item } & \multicolumn{1}{c|}{ Content } \\
\hline \multirow{2}{*}{$\begin{array}{c}\text { Review of } \\
\text { engineering } \\
\text { parameters }\end{array}$} & $\begin{array}{l}\text { 1. Special analysis and review of the } \\
\text { change of water level and flow; } \\
\text { 2. Rechecking of the discharge curve of } \\
\text { 3. Rechecking of design parameters for } \\
\text { temporary water retaining structures. }\end{array}$ \\
\hline \multirow{5}{*}{ specific analysis } & $\begin{array}{l}\text { 1. Analysis and Study on the } \\
\text { characteristics of rainstorm and flood; } \\
\text { 2. Analysis and study of climate } \\
\text { characteristics; } \\
\text { 3.Analysis and study of disastrous } \\
\text { weather; } \\
\text { 4.Analysis and study of quantitative } \\
\text { precipitation forecast in River Basin; } \\
\text { 5.Analysis and Study on the } \\
\text { characteristics of water and sediment and } \\
\text { the change of erosion and siltation; } \\
\text { 6.Analysis and Research on operation } \\
\text { influence of upper and lower hydropower } \\
\text { stations. }\end{array}$ \\
\hline
\end{tabular}

\subsection{Information release}

Hydrometeorological forecast information, important water information, disaster weather warning information, and special analysis and other research results were completed and released according to different user needs. The information release is mainly by telephone and the mobile phone short message, e-mail, fax and so on as the auxiliary means. Information release adopts the combination of automatic release and manual release, and regularly combs and confirms the issue.

\subsection{Emergency management}

Establish the emergency organization of Hydrometeorological support, the mechanism of emergency disposal and the duty of personnel at all levels. When there are special cases such as equipment failure, network communication failure, and super standard flood, we will start the emergency plan, submit information on emergency according to the relevant requirements, and organize the post investigation and analysis.

\subsection{Data compilation}

Regularly carry out meteorological and hydrological data reorganization and filing, including basin and dam basic hydrological and meteorological data, flood emergency plan, meeting summary, project technical report, hydro meteorological briefing, and technical summary. The reorganization of the data is kept in the form of paper and electronic $\mathrm{CD}$.

\section{Quality evaluation of Hydrometeorological service}

\subsection{The automatic system of hydrologic data collection and transmission}

Quality evaluation for an automatic system of hydrologic data collection and transmission can be used in the System unimpeded rate and system availability

(1) System unimpeded rate

$$
M=T / N
$$

Where: $\mathrm{M}$ is the unimpeded rate of the telemetering station in the statistical time period; $\mathrm{T}$ is the sum of the number of times the telemetry station actually reported; $\mathrm{N}$ is the sum of the number of times the telemetry station should report.

(2) system availability

$K=(P-G) / P$

Where: $\mathrm{K}$ is the system availability in the statistical time period; $\mathrm{P}$ is the total operating time of each station in the assessment period; $G$ is the sum of the abnormal running time of the system stations in the assessment period.

\subsection{Quality evaluation of hydrological forecast}

The quality evaluation index of the hydrological forecast mainly is the forecast of the flow and water level of the dam area, and evaluates the process of annual, flood period, low water period, monthly, and secondary flood. Among them, the prediction method is adopted for the quality evaluation of the flow forecast, and the absolute error method is adopted for the water level prediction and evaluation. The evaluation standard is implemented in the relevant regulations of GB/T 22482 hydrological information and prediction standard.

\subsection{Quality evaluation of meteorology forecast}

The quality evaluation of meteorology forecast includes 24 hours of the highest and lowest, average temperature forecast, 24 hours in the weather forecasting, quantitative precipitation forecasting, disaster weather forecast. The specific evaluation indexes and methods are shown in Table 5. 
Table 5.Quality evaluation index and method of meteorological forecast

\begin{tabular}{|c|c|c|}
\hline Evaluation items & Evaluation index & Evaluation method \\
\hline $\begin{array}{l}\text { Prediction of the } \\
\text { maximum, minimum and } \\
\text { average temperature in } \\
\text { the next } 24 \mathrm{~h} \text { of the dam } \\
\text { area }\end{array}$ & accuracy rating & $\begin{array}{l}\text { 1.Accuracy rating of temperature prediction }=\text { Correct } \\
\text { number of forecasts/Total number of forecasts* } 100 \% \text {; } \\
2 . \mid \text { forecasting- actuality } \mid \leqslant 2{ }^{\circ} \mathrm{C} \text { is correct; }\end{array}$ \\
\hline $\begin{array}{l}\text { Forecast of the weather } \\
\text { forecast and quantitative } \\
\text { precipitation in the next } \\
24 \text { hours of the dam area }\end{array}$ & accuracy rating & $\begin{array}{l}\text { 1.The forecasting accuracy rate of the weather }=\text { Correct } \\
\text { number of forecasts/Total number of forecasts* } 100 \% \text {; } \\
\text { 2.The forecasting accuracy rate of the rainfall }=\text { The sum of } \\
\text { the forecast score s/Total number of forecasts* } 100 \% \text {, } \\
\text { Forecast score according to table } 6 .\end{array}$ \\
\hline $\begin{array}{c}\text { Forecast of disastrous } \\
\text { weather }\end{array}$ & accuracy rating & $\begin{array}{c}\text { 1.Accuracy rating }=\text { Correct number of forecasts/(Total } \\
\text { number of forecasts- The number of missing } \\
\text { reports)* } 100 \% \text {; } \\
\text { 2.Empty alarm rate }=\text { Number of empty alarm /Total } \\
\text { number of forecasts* } 100 \% \text {; } \\
\text { 3.False negative rate }=\text { Number of false negative / Total } \\
\text { number of forecasts* } 100 \% * 100 \% \text {. }\end{array}$ \\
\hline
\end{tabular}

\subsection{Service Quality Evaluation}

Evaluation of service quality of hydrometeorological information bulletin, forecast and warning information release, emergency response and so on. The evaluation indexes and methods are shown in Table 6:

Table6. Evaluation index and method of service quality

\begin{tabular}{|c|l|l|}
\hline $\begin{array}{c}\text { Evaluation } \\
\text { items }\end{array}$ & $\begin{array}{c}\text { Evaluation } \\
\text { index }\end{array}$ & \multicolumn{1}{c|}{ Evaluation method } \\
\hline $\begin{array}{c}\text { Live } \\
\text { information } \\
\text { and } \\
\text { forecasting } \\
\text { and warning } \\
\text { information } \\
\text { release }\end{array}$ & Effectiveness & $\begin{array}{l}\text { 1.Effectiveness = Number of } \\
\text { qualified information / Total } \\
\text { number of information*100\%; } \\
\text { 2.Forecasting: completion of the } \\
\text { information release is judged to } \\
\text { be qualified within half an hour } \\
\text { after the forecast is completion; } \\
\text { 3.Warning: completion of the } \\
\text { information release is judged to } \\
\text { be qualified within 5 minutes } \\
\text { after the early warning content is } \\
\text { determined. }\end{array}$ \\
\hline Emergency & & $\begin{array}{l}\text { In accordance with the } \\
\text { corresponding plan or emergency } \\
\text { response } \\
\text { measures, emergency response to } \\
\text { emergencies, as timely and } \\
\text { correct disposal. }\end{array}$ \\
\hline
\end{tabular}

\section{Conclusion}

Through Three Gorges, Xiangjiaba, Xiluodu power station which has been completed giant engineering practice, and Wudongde Baihetan, etc. in the construction of continuous improvement, hydrometeorological support during construction period of Large Hydropower Project meteorological has been mature, and remarkable achievements have been made in the fields of main channel closure, catastrophic weather forecast and warning, and temperature control of concrete $^{[4]}$. Through the long and short term forecast and severe weather warning, special weather forecast and other forms, the construction period of the hydrological meteorological work provides important technical support for flood control and construction schedule ${ }^{[5]}$. With the gradual deepening of hydropower development in developing countries, the scale of the cascade basins will be bigger and bigger. The role of hydrological and meteorological support services will become more and more important. How to establish a set of effective hydrometeorological service management system in the construction period of a cascade hydropower station is a problem for every hydropower builder to think about.

\section{Acknowledgment}

1. "Yangtze River water resources development and protection strategy and key technology research" project.(2019YFC0409000).

2. National key basic research and development program (973 Program) funded project (2013cb036406) ; 3. Water special project of the 12th Five Year Plan(2014ZX07104-005)

\section{References}

1. KUANG Yiyu, WAN Hansheng, ZILi. The practice of long - term hydrological forecasting of cascade hydropower projects during the construction period in Jinsha River. Yangtze River, Vol.42, No.6(2011).

2. SHEN Huying, YANG Wenfa, Li Xiaolin. Hydrometeorological forecast for TGP's main river closure. Yangtze River. No.6(1999).

3. LIU Chuanzheng, WEN Mingsheng, TANG Can. Meteorological early warning of geo-hazards in China based on raining forecast.Geological Bulletin Of China. Vol.23, No.4(2004).

4. ZHANG Chengwen,ZENG Tingyu,ZONG Dexiao. Meteorological support services reflections on Baihetanhydropower plant in construction period.Journal of Yunnan University. Vol.34, (2012).

5. HUANG Zhongshu. Hydrometeorologic forecast for Three Gorges Project river closure. Yangtze River, Vol.27, No.10(1996). 